\title{
The Experience and Inspiration for Mainland China of Preened Funeral Arrangement in The United States and Taiwan
}

\author{
Dengfeng Hua \& Yiyang Fan \\ Business School, University of Shanghai for Science and Technology \\ Shanghai 200090, China \\ E-mail: Helen-hdf@126.com \\ The research is financed by the Innovation Fund Project for Graduate Student of Shanghai (No. JWCXSL0902).
}

\begin{abstract}
Preened funeral agreement is a contract of planning a series of issues after the death during his lifetime. The contract can greatly reflect the life planning, and respect for the man's personal wishes. Preened funeral agreement has carried out quickly in the United States, Canada and Japan with many experiences. It is very significant for mainland China to Sum up the experience in United States and Taiwan, with the advent of the aging time, the social security system is in transition. It is necessary to learn from their experience and build up preened funeral agreement.
\end{abstract}

Keywords: Aging, Preened funeral agreement, Planning, Social Security

\section{What is the preened funeral agreement?}

Kongzi says: "When a person is alive, treat him according to etiquette, when a person dies, bury him according to etiquette, and pay homage to him accordance with the courtesy." "Life and death are both great," he says, "death is the renewal of life," and we need to respect life and see death matters as life. Tagore once said: "One has no plans of life is like a ship without direction." the peaceful attitudes of life and death from Sages reflect the broad-minded human beings of "from start to finish," but also reflects the eager to life-plan. The preened funeral agreement reflects the attitude of life and death "from start to finish", and the ultimate breadth of life care.

The preened funeral agreement in The United States refers to prepare his burial, which stresses the "contractual nature", while Japanese preened funeral agreement stressed setting their own funeral program and without trouble to the survivor. In this paper, we use the definition which Long Deng, Youzhi Huang have given in 2007. Preened funeral agreement refers to "A contractual guarantee support to consumers, before signing the contract, the funeral industry should show the funeral-related information and related services or goods". For consumers, if they prepared in advance for their funeral matters, they will have peace of mind and a greater courage to face the rest of his life. Sometimes, the remaining issues after the death of are quite cumbersome, such as a variety of procedures of death, transform of ownership of property, and these can be mostly entrusted to a lawyer or accountant, the funeral and burial matters after the death is a scope of preened funeral agreement. but in aging society, not only those who are reborn in the "die" issue, as well as comforting senior partner's emotion, the sacrificial support of the dying by the follow-up, and supporting old people matters, hospice care, dignity, maintenance, etc. family members is difficult to deal with those things comprehensively with grief. If a holistic approach to customer service adopted, the situation will be greatly changed.

Perfect service system contains related services about mainly the lives of senior citizens, medical, psychological, legal, property, and funeral form a strategic alliance with all the related industries, creating an organic network of close cooperation. This would be a powerful system combined the funeral services with social welfare, medical, legal, religious, consulting and other professional services together, and build an environment of powerful performance and create the ultimate all-round care service system.

\section{2. the functions and features of preened funeral agreement in America and Taiwan region}

\subsection{Functions}

In the aging society, a large number of old people need to rely on self-reliance aspect of family, social welfare and convenience of the region from a life of self-care and the economy. The preened funeral agreement has the function to prepare for the future and the funeral matters when the old people are in economic self-sufficiency. From the perspective of an aging society, the implementation of preened funeral agreement has the following three functions:

1) Information sharing, exchange of experiences. Including concepts related to the spread of Pure and information to the public.

2) Value clearing. Can help individuals form a correct understanding of death and resist unhealthy effects. 
3) Services Arrangements. Can affect the old people with the positive and healthy attitude to arrange the funeral, arrange legal issues, and health insurance.

\subsection{Features}

The preened funeral agreement In the United States and Taiwan have the characteristics of the following points:

1) Industry has the responsibility to make contractual services for publicity and explanation.

2) This will put an end to previous consumers who lacking of understanding of relevant information and can not be implemented effectively choice, and this can provide personal characteristics of the funeral service options. It will be greatly different from the traditional funeral.

3) Consumers can choose services and goods.

4) The nature of the preened funeral agreement is for consumers personalized service. Consumers will choose the right products and services based on their consumption capacity, as well as the families of the views and religious beliefs.

5) Consumers have the right to unilateral termination.

6) The service will be got in the future, people can not fully grasp the risk, and therefore, without prejudice to the rights of the company, the consumer should have the right to terminate a contract. Or, the freedom and flexibility conception should also be equipped in the contract. This is guaranteed by law.

7) The signing of contracts should respect the wishes of customers.

8) During the traditional funeral, the families based on customs often spend a lot of money but have the better result. The contracting parties will need to be respected, when the parties do not have the "capacity", the can be down by family members under the provisions of the law guardians of the sign.

9) The price of the preened funeral agreement is clear and open.

10) The preened funeral agreement has a clear sense of charges. In the face of inflation pressures, companies need to estimate the cost.

11) Fees of the preened funeral agreement under preservation and safely operation.

12) Foreign fund are managed by professional insurance companies for investment to achieve the preservation and appreciation.

13) Process standardization, process transparency. Simple, dignified, distinguished, 24 hours and personalized service, family members can be assured of professional service staff who with a clean image and a professional knowledge.

14) The Government has clear regulatory measures.

15) Can be used as investment tools to reject to inflation.

\section{The experiences of the preened funeral agreement in America and Taiwan region}

\subsection{The experiences of the preened funeral agreement in America}

The preened funeral agreement has been implemented for half a century in the United States, which has accumulated much experience and there are also some problems.

(A) Promotion and sell of the preened funeral agreement

in the United States, more than $43 \%$ of old people who above 50 have been introduced the preened funeral agreement about funeral. Of which up to $44 \%$ in Ohio Erie, Rue-state of $29 \%$ is min; more than $39 \%$ of people over the age of 50 have received introduction about the preened funeral agreement of burial. The proportion of Erie is the lowest $28 \%$ of the state. Up to $32 \%$ of people more than 50 years of age have bought the products. The proportion in Alabama, Pennsylvania is high, and in California and Illinois is low. (See Table 1)

(B) the purchase of goods and services

In all purchased goods and services, cemetery (tower-bit, tomb) at the highest proportion, accounting for $27 \%$, tombstone (coffins, graves) second, accounting for $18 \%$. From the perspective of state, the purchase of cemetery (tower-bit, tomb), the largest is in Alabama and Pennsylvania, respectively, $42 \%$ and $40 \%$, at least in California, for $26 \%$. Other goods and services are also similar, Alabama and Penn State ran up respectively $34 \%$ and $27 \%$, and the least proportion is $19 \%$ of California. (See Table 2)

(C) The payment of the preened funeral agreement

The proportion of leasing payments of the preened funeral agreement about funeral in the United States is $41 \%, 47 \%$ payable in installments. Illinois, Pennsylvania, Ohio and California prefer a lump sum, the ratio were $66 \%, 63 \%, 60 \%$ and $50 \%$, Alabama, on the contrary, like the lump-sum payment is greater than the proportion of installment, 
respectively, $42 \%, 37 \%$.

Considering the preened funeral agreement about burial, the Americans prefer a lump sum, there are $60 \%$ of the lump-sum option, the sampling of the five states also prefer lump-sum payment. (Table 3)

(D) The use of the fund

The fund of the preened funeral agreement collected is usually placed on the trustiest fund to invest in universal life insurance, the rate is up to $30 \%$, the proportion of Illinois also reached $28 \%$, and other types of investment accounts for $14 \%$. There are also a high percentage of people who do not know the flow of funds paid by California, $60 \%, 56 \%$ in Alabama. (See Table 4)

(E) The specifications

U.S. states made different transaction management standards of the preened funeral agreement, the difference is quite big. States also have the different legal norms of the consumers to purchase a cemetery deeds. For example, California provides funeral goods and services, fees and charges all join the trust, the provisions of 30 percent in Florida, Maryland, and the payment of the Trust Deed provides that $100 \%$ of the trust during his lifetime, the coffin $80 \%$ of the trust; to allow the administrative costs of the trustee may withdraw California administrative costs, but not more than $4 \%$, Florida is not limited to the amount of the provisions of New York State administrative costs must not exceed $1 \%$ of the 0.75 trust fund shall be expressly mentioned; contract can be revoked; in the termination of the trust, consumers are given full contractual payments, the California provides to recover $100 \%$ of the principal plus interest, subject to the deduction does not exceed $10 \%$ of the principal amount of administrative costs and to recover the costs, the provisions of Florida consumers can recover all the principal within 30 days, but the interest owned by the seller; Trust deposited in the fund, the California provision may, under certain conditions, to buy government bonds, government-guaranteed securities, the Federal Deposit Insurance Corporation guarantees bank, or certain funds only exist in Florida provides a national or state bank or trust company, Maryland, the agreement requires the existence of the fund to pay the assignee's interest-bearing accounts or the federal guarantee of bank trust accounts, New York, the fund shall be deposited in interest-bearing bank accounts; fund investment channels, the Florida offer a variety of different investment channels, Maryland require more stringent New York State is not allowed investment; another Florida also building consumer compensation fund to compensate for damage caused due to investment failure of consumers, each extract 1 U.S. dollars, Texas has a similar provision.

\subsection{The experiences of the preened funeral agreement in Taiwan}

The preened funeral agreement in Taiwan has progressed not long age, obvious advantages and problems exposed with the gradual unfolding.

There is hundreds of Contract manufacturers in Taiwan, and mostly of them are small companies. Only five or six companies have certain scale, while most of them make regional promotion. To the end of 2004, the preened funeral agreement outstanding to 10 million, accounting for $5 \%$ of the total market, however, compared with the life insurance, Taiwan still has much room for development.

Deng Long, and Huang showed that the development of preened funeral agreement in Taiwan is still "embryonic period", although a variety of information on websites and attractive to consumers, but the system is still far from mature. They sum up the status of development of the preened funeral agreement of the following aspects:

a) Consumer protection mechanisms are inadequate. Because of the preened funeral agreement performance time of uncertainty, the longer the higher the risk for consumers. Businesses closed down or are not operated or unilaterally increase the protection of consumer rights when there are suitable arrangements yet.

b) The relevant laws and regulations are not sound. As mentioned earlier, the U.S. state of his lifetime contract requirements are more detailed, but Taiwan was only a simple 12 laws and regulations referred to. When face disputes, consumers become vulnerable groups easily.

c) Tips are not clear. Majority of the Taiwan-related services, many websites in order to function promotion points as a lifetime contract finance and investment, but often after the signing of contracts, the two sides there will be greater awareness of performance gaps, while the United States and Japan, as Taiwan does not have the provisions of the industry without at regular intervals to provide consumers with the latest service changes, so when the huge performance gap is likely to affect consumers adversely.

d) No arbitration for dispute. NPO non-profit charitable organizations involved in operations in Japan, while only merchants and consumers, no comparable full-time institution or organization in Taiwan.

e) There is no management oversight system. The preened funeral agreement with complicated rituals and processes are determined by the services and goods. Without accompanying regulatory system, companies has a lot of space not follow the agreed implementation, this will result in the adverse development of the industry. The need for official or private management of organizations has credibility. 
f) There is no proper mechanism for compensation. In accordance with experience in tourism in the United States, "the compensation norms and mechanisms" set up, once the relevant companies can not perform or fail, consumers have access to the relevant damages to the funeral industry guild UNPROFOR way. In this way, the benefits of consumers are safeguarded. In addition, Florida and Texas have established a specifically compensation fund to deal with such situations. Taiwan has no corresponding mechanism.

g) A signing bonus of trust enforced. The law asked $75 \%$ of preened funeral agreement fund to deliver to consumers trust in Taiwan region, but most companies have not yet implemented.

h) Poor representations channels for consumers. Because the preened funeral agreement contract goes in front of the government administration and regulations, lack of sound management and norms. there is no professional consumer protection mechanisms, when the concentration of the first contract to fulfill, it will surely generate a large number of representations, there is no such channel, which will be a heavy blow for consumer confidence, and is not conducive to social stability and industry development.

\section{4. the inspiration of the preened funeral agreement for mainland China}

\section{1conform to the aging requirements, Shanghai will be able to carry out related activities appropriate}

Today, there are more and more common scheduled funeral services in foreign countries: Europe and the United States has more than 60 years of history, SUNLIFE have carried out this business more than 40 years in Japan, the total number of customers $25 \%$ of the population to participate in the business in Canada, the promotion and popularization of Taiwan is growing rapidly in recent years. With the aging of the further acceleration of big cities like Shanghai, there is the feasibility to carry out this service. Detailed analysis is as follows:

a) Comply with the people-oriented, in line with world trends. In line with the thinking of people-oriented with reference to the world's development trend, China has a real basis of the reforms, and experiencing the old-age insurance reform and medical insurance after the reform of socialization can be a gradual improvement of the social security system.

b) China Life Insurance has great potential, citizens continue to focus on improving the quality of life, and people will be more eyes to life a variety of preparations. People do master their own lives to complete their life choices in their own way, without causing financial burden on their families, while the completion of the funeral rites professional staff. This is also a manifestation of those died who caring for family members

c) The status in line with aging society in Shanghai. As described by the former Shanghai, China cities with the highest degree of aging, one of the aging rates of $20 \%$, but aging is accelerating. It is predicted that after 2016, Shanghai will reach the peak of population aging, increase old-age security efforts is a major task in Shanghai. At the same time, the process of an aging population in Shanghai has also shown a significant phenomenon of the empty nest. By the end of 2008, Shanghai's pure old family size and the number of older persons living alone, respectively, 863.8 thousand and 188 thousand people, the elderly dependency ratio in 2008 was $30.8 \%$ in 2050 is expected to reach $90.1 \%$. The aging of the serious situation prompted greater attention to social matters, after the old life, which also provided the conditions to carry out during his lifetime lease.

d) Have a certain basis of public opinion, there is potential demand. Shanghai's aging into a contract similar to the product produced during his lifetime consumer groups, old-age dependency coefficient increases was also reasonable and the next generation of people think about how previous generations lived and died reduce the family burden. Longhua Funeral Parlor issue has been investigated in this regard. The results showed that: In the 300 people surveyed, $18 \%$ of the people expressed an understanding of his lifetime contract similar products, for carrying out such operations an affirmative attitude toward the more than $90 \%, 25 \%$ of people said that they could purchase, educated, high income people a higher degree of recognition of this service.

\subsection{Shanghai needs carried out in the form of an insurance-based}

The key of the preened funeral agreement prevalent in Europe and the United States is its high degree of legal, industry management standards, and the matured market. However, in Mainland China because of the funeral industry, industrial background, policies and regulations and many other reasons, it is still difficult to fully use foreign trust model in China. The following reasons:

a) The preened funeral agreement contains the tomb of the intended function, which contrary to the current "cemetery Interim Measures" which provides "no pre-graves" in our country.

b) Funeral services and grave of the preened funeral agreement can be transferred. The transfer will have to repeat purchase, so easily lead to speculative trading, which in China is strictly prohibited, and indeed such a thing happened a few years ago.

c) The preened funeral agreement to pay only according to the provisions of the preferential terms of the amount, the industry will be a certain amount of funds required a certain degree of investment; Chinese funeral business is not yet 
possesses such qualifications.

d) Chinese development of trust lags behind insurance, and its capital management capacity is limited.

2) Therefore, carrying out such activities to meet several conditions in Shanghai: First, with approximate funeral service functions abroad; second, not in violation of national and financial aspects of the civilian aspects of the relevant laws and regulations; third, consumer, industry, business and social interests capable of integration; last, with realistic operational.

\subsection{To carry out should learn from Taiwan's experience at the beginning, legislative and regulatory ahead}

Carrying out the preened funeral agreement should be based on the experience of the United States and Taiwan. And this to needs of large national laws, regulations, industry regulation and self-discipline agreement, also need a robust consumer protection mechanism, a professional arbitration body, and then a clear statement. We need to guide relevant enterprises of products and services and provide consumers with the freedom of individual choice. Legislation is modeled on the U.S. idea, but our country due to non-federal system does not require the provinces are located in the law requires only the basic legal provisions of national unity, where the local industry association issued in accordance with local circumstances can be relevant agreements.

\section{References}

AARP. (2003). Older Americans and Preened Funeral and Burial Arrangements: Findings from a Five-State Telephone Survey" .[Online]Available:http://research.aarp.org/consume/d16993_state.pdf.

Congress Accounting Office, [Online] Available: http: // www.gao.gov/archive/1999/gg999156.pdf.

Keiko Kitagawa. (2003). the last period of life issues and the preened agreement for senior citizens, Kyushu University Press. 277.

Wenlong Deng, Youzhi Huang. (2007). Analysis of Taiwan's preened agreement development. The Shanghai International funeral services Symposium Proceedings.

Xinyi Liu. (2004). The Study of Preened in America. Chiayi country Taiwan: Nanhua University.

Youzhi Huang. (2002). the studies on the preened funeral agreement management. NO. 48.

Table 1. the communication ratio and purchase ratio in America and five states of people above the age of 50 (Unit: \%)

\begin{tabular}{|l|l|l|l|l|l|l|}
\hline & Nationwide & Alabama & Pennsylvania & Illinois & Ohio & California \\
\hline Communication ratio (funeral) & 43 & 40 & 38 & 29 & 44 & 42 \\
\hline Communication ratio (burial) & 39 & 39 & 36 & 28 & 44 & 42 \\
\hline purchase ratio & 32 & 48 & 44 & 34 & 42 & 37 \\
\hline
\end{tabular}

Date from: AARP. (2003). Older Americans and Preened Funeral and Burial Arrangements: Findings from a Five-State Telephone Survey [Online] Available: http:// research.aarp.org/ consume/ d16993_state.pdf. Xinyi Liu. (2004). The Study of Preened in America. Chiayi country Taiwan: Nanhua University.

Table 2. the purchase in America and five states of people above the age of 50 (Unit: \%)

\begin{tabular}{|l|l|l|l|l|l|l|l|l|l|l|l|l|l|}
\hline & \multicolumn{2}{|l|}{ Nationwide } & \multicolumn{2}{l|}{ Alabama } & \multicolumn{2}{l|}{ Pennsylvania } & \multicolumn{2}{l|}{ Illinois } & \multicolumn{2}{l|}{ Ohio } \\
\hline & $50+$ & $\begin{array}{l}\text { Has } \\
\text { purchased }\end{array}$ & $50+$ & $\begin{array}{l}\text { Has } \\
\text { purchased }\end{array}$ & $50+$ & $\begin{array}{l}\text { Has } \\
\text { purchased }\end{array}$ & $50+$ & $\begin{array}{l}\text { Has } \\
\text { purchased }\end{array}$ & California \\
\hline $\begin{array}{l}\text { Cemetery } \\
\text { tower-bit) }\end{array}$ & 27 & 86 & 42 & 88 & 40 & 91 & 31 & 90 & 39 & 94 & $\begin{array}{l}\text { Has } \\
\text { purchased }\end{array}$ & 26 & 70 \\
\hline $\begin{array}{l}\text { Tombstone } \\
\text { coffin) }\end{array}$ & 18 & 58 & 34 & 71 & 27 & 62 & 18 & 54 & 25 & 60 & 19 & 50 \\
\hline $\begin{array}{l}\text { Funeral } \\
\text { Services }\end{array}$ & 13 & 40 & 22 & 46 & 19 & 43 & 15 & 43 & 16 & 40 & 14 & 38 \\
\hline All buyers & 9 & 30 & 18 & 38 & 15 & 35 & 11 & 35 & 15 & 35 & 10 & 28 \\
\hline
\end{tabular}

Date from: the same as table 1. 
Table 3. the way of purchase in America and five states of people above the age of 50 (Unit: \%)

\begin{tabular}{|c|c|c|c|c|c|c|}
\hline & Nationwide & Alabama & Pennsylvania & Illinois & Ohio & California \\
\hline Funeral & 41 & 37 & 63 & 66 & 60 & 50 \\
\hline installment & 47 & 42 & 20 & 16 & 22 & 36 \\
\hline Funeral & 60 & 49 & 63 & 67 & 64 & 54 \\
\hline Funeral & 28 & 24 & 21 & 14 & 18 & 26 \\
\hline
\end{tabular}

Date from: the same as table 1.

Table 4. the way of investment in America and five states of people above the age of 50 (Unit: \%)

\begin{tabular}{|l|l|l|l|l|l|l|}
\hline & Nationwide & Alabama & Pennsylvania & Illinois & Ohio & California \\
\hline Trust Fund (Funeral) & 31 & 15 & 20 & 24 & 27 & 19 \\
\hline Life Insurance (Funeral) & 30 & 21 & 17 & 28 & 11 & 14 \\
\hline Other investments (funeral) & 14 & -- & 7 & 5 & 1 & 3 \\
\hline Trust Fund (burial) & 4 & 8 & 10 & 13 & 9 & 12 \\
\hline Life Insurance (burial) & 16 & 16 & 14 & 12 & 7 & 8 \\
\hline Other investments (burial) & 5 & -- & 3 & 3 & 3 & 3 \\
\hline
\end{tabular}

Date from: the same as table 1. 